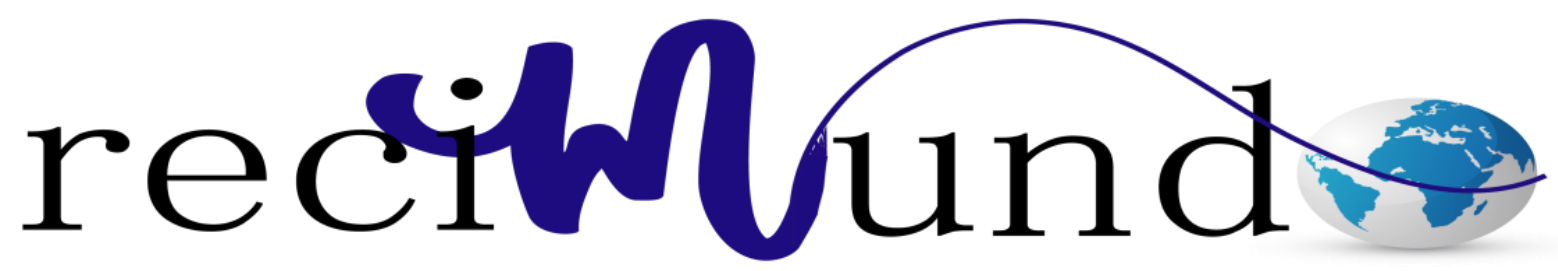

Revista Científica Mundo de la Investigación y el Conocimiento

Juan Antonio Vera Hinojosa ${ }^{a}$; Jefferson Steven Rivera Moreira ${ }^{\text {b; }}$ Delia Jamiley Naranjo Piña; Delia María Andaluz León ${ }^{c}$

Enfermedades respiratorias asociadas al ciclo lluvioso

Respiratory diseases associated with the rainy cycle

Revista Científica Mundo de la Investigación y el Conocimiento. Vol. 2 núm.3, julio, ISSN: 2588-073X, 2018, pp. 564-577

DOI: 10.26820/recimundo/2.(3).julio.2018.564-577

Editorial Saberes del Conocimiento

Recibido: 05/04/2018 Aceptado: 04/06/2018 Publicado: 30/07/2018

Correspondencia: juanantonioverahinojosa@gmail.com
a. Médico; juanantonioverahinojosa@ gmail.com
b. Médico; jeff_ribery@hotmail.com
c. Médico; delimarandaluz@ hotmail.com
d. Médico; deliapm2011@ hotmail.com 


\section{Enfermedades respiratorias asociadas al ciclo lluvioso}

Vol. 2, núm. 3., (2018)

Juan Antonio Vera Hinojosa; Jefferson Steven Rivera Moreira; Delia Jamiley Naranjo Piña;

Delia María Andaluz León

\section{RESUMEN}

Evidente ha sido el impacto que el cambio climático ha causado en diversos ámbitos de la sociedad, y la salud viene siendo uno de los aspectos más importantes. Aunque los efectos que estos cambios climáticos ejercen sobre la salud están asociados especialmente al aumento de la frecuencia y dimensión de eventos climáticos extremos, y también de manera general con el incremento de la temperatura y al aumento/disminución de la precipitaciones, la presente entrega se enfocó en proporcionar un material didáctico y vigente respecto a las enfermedades respiratorias que se asocian al ciclo lluvioso de países tropicales, puesto que precisamente es en dicha etapa estacional que cada vez más se percibe la prevalencia de estos casos endémicos en la región. Para este fin, se ha adelantado una investigación documental a nivel descriptivo, puesto que, reiterando, la idea que se ha tenido es la de aportar un material informativo de fácil comprensión, que bien pudiera servir de fundamento en investigaciones más específicas. Se logra concluir que, si bien es necesario seguir abordando la solución a estas particularidades desde una perspectiva interdisciplinaria, en la que siempre es imprescindible considerar la fragilidad de cada región en particular, en específico las asociadas a condiciones socioeconómicas, presente mayormente en países tropicales, resulta que más importante es, (tal y como inicia la mayoría de las recetas y tratamientos médicos) tomar conciencia y responsabilidad temprana en cuanto a las previsiones que cada individuo puede adoptar para minimizar al máximo las complicaciones de las enfermedades respiratorias aquí descritas.

Palabras clave: Salud, eventos, precipitaciones, enfermedades, tropicales. 


\title{
Enfermedades respiratorias asociadas al ciclo lluvioso
}

Vol. 2, núm. 3., (2018)

Juan Antonio Vera Hinojosa; Jefferson Steven Rivera Moreira; Delia Jamiley Naranjo Piña; Delia María Andaluz León

\begin{abstract}
Evident has been the impact that climate change has caused in various areas of society, and health has been one of the most important aspects. Although the effects that these climatic changes exert on health are especially associated with the increase in the frequency and dimension of extreme weather events, and also generally with the increase in temperature and the increase / decrease in rainfall, the present delivery is focused on providing a didactic and current material regarding respiratory diseases that are associated with the rainy cycle of tropical countries, since it is precisely in this seasonal stage that more and more the prevalence of these endemic cases in the region is perceived. For this purpose, a documentary research has been carried out at a descriptive level, since, reiterating, the idea that has been had is to provide easily understandable information material, which could well serve as a basis for more specific research. We conclude that, although it is necessary to continue addressing the solution to these particularities from an interdisciplinary perspective, in which it is always essential to consider the fragility of each region in particular, specifically associated with socioeconomic conditions, present mainly in tropical countries, it turns out to be more important, (as most medical prescriptions and treatments start) to become aware and early responsibility regarding the predictions that each individual can adopt to minimize the complications of the respiratory diseases described here.
\end{abstract}

Keywords: Health, events, rainfall, diseases, tropical. 


\section{Enfermedades respiratorias asociadas al ciclo lluvioso}

Vol. 2, núm. 3., (2018)

Juan Antonio Vera Hinojosa; Jefferson Steven Rivera Moreira; Delia Jamiley Naranjo Piña;

Delia María Andaluz León

\section{Introducción.}

En base a la información aportada por la Organización Mundial de la Salud (OMS), los fenómenos meteorológicos extremos son cada vez más intensos y frecuentes, particularmente, los regímenes de lluvias están cambiando. (OMS, 2018)

Las manifestaciones derivadas del fenómeno medioambiental; tales como fuertes lluvias, calor excesivo, huracanes o los bruscos cambios de clima, son considerados como el conjunto de factores incidentes en la trasmisión de enfermedades. Especialistas como Arturo Martínez, afirman que los efectos del cambio climático hacen más fácil la transmisión de enfermedades infecciosas, especialmente las respiratorias, por los cambios que se ocasionan en el sistema inmunitario. (Agencia EFE, 2017)

A nivel local, podría hacerse mención a una data relativamente reciente aportada por la Organización Mundial de la Salud (OMS), que hasta los momentos podría considerarse como la fuente formal idónea. En el documento informativo conocido como "Perfiles de enfermedades no transmisibles, 2014" se estimó que, de las 81.000 muertes ocurridas en Ecuador para ese año, el 4\% fue asociado a enfermedades respiratorias crónicas (incluidas todas las edades de ambos sexos) ${ }^{1}$. (OMS, 2015)

La idea que se persigue en el presente trabajo ha sido la de exponer de manera específica sobre las enfermedades respiratorias vinculadas a los períodos lluviosos que se manifiestan particularmente en regiones tropicales. Se ha tenido claro que, si bien es cierto que de esta

1 En ese documento se aclara que las estimaciones de mortalidad tienen un alto nivel de incertidumbre porque no están basados sobre ningunos datos nacionales sobre mortalidad por Enfermedades No Trasmisibles. 


\section{Enfermedades respiratorias asociadas al ciclo lluvioso}

Vol. 2, núm. 3., (2018)

Juan Antonio Vera Hinojosa; Jefferson Steven Rivera Moreira; Delia Jamiley Naranjo Piña; Delia María Andaluz León

temática pudiera encontrarse estudios amplios y suficientes, no es menos cierto que con este material también se puede aportar información vigente, aludiendo a los datos más reciente que, al respecto, se hallen al momento del proceso de investigación emprendido, lo entonces pudiera servir de fundamento a posteriores investigaciones.

Posterior al análisis y discusión de la información recabada en este trabajo investigativo, se concluirá haciendo referencia a las consideraciones a las que hubiere lugar, mismas que corresponderán con el criterio del equipo investigador y con la opinión de especialistas en el tema planteado, quedando a discreción del lector darle el valor informativo e investigativo que considere pertinente.

\section{Materiales y métodos.}

Se realizó una investigación de tipo documental a nivel descriptivo, basada en fuentes especializadas y bases de datos de carácter formal y profesional, tales como: libros, revistas, artículos científicos, boletines informativos, informes, trabajos investigativos de tercer y cuarto nivel académico, así como también información alojada en bases de datos digitales accedidas a través de portales web. En ésta investigación se ha respetado el principio de actualidad, pertinencia, autoría y veracidad del contenido seleccionado.

Respecto a la metodología aplicada, Ríos (2017) afirma que la investigación documental “...recurre a la consulta de documentos para obtener sus resultados”. En cuanto a la profundidad de la misma, explica que la investigación es considerada a nivel descriptivo cuando “...busca encontrar las características, comportamiento y propiedades del objeto de estudio, ya sea en el presente o en el futuro..." (p.81). 


\section{Enfermedades respiratorias asociadas al ciclo lluvioso}

Vol. 2, núm. 3., (2018)

Juan Antonio Vera Hinojosa; Jefferson Steven Rivera Moreira; Delia Jamiley Naranjo Piña;

Delia María Andaluz León

\section{Resultados.}

De acuerdo con la OMS, "las enfermedades respiratorias afectan a las vías respiratorias, incluidas las vías nasales, los bronquios y los pulmones. Incluyen desde infecciones agudas como la neumonía y la bronquitis a enfermedades crónicas como el asma y la enfermedad pulmonar obstructiva crónica" (OMS, 2018)

Instituciones oficiales de países como Colombia, por ejemplo, han emitido alertas en relación al aumento de las lluvias en sus latitudes, puesto que argumentan que ellas tienen que ver con la aparición de más casos de infecciones respiratorias agudas (IRA). Explican que ese tipo de infecciones son las más frecuentes en la salud humana y ocurren por medio distintos microorganismos que afectan el aparato respiratorio, que van desde las más comunes, como el resfriado, hasta las más duras, como en el caso de las neumonías, que pueden ser mortales si no se les tratan a tiempo y de forma adecuada. (El Tiempo, 2018)

La misma fuente informativa agrega que el Instituto Nacional de Salud del mencionado país ha afirmado que "el aumento de lluvias no solo motiva la circulación de los virus en el ambiente, sino que el frío disminuye la capacidad inmunológica de las personas” (párr. 6). Inclusive, la misma institución asegura que está comprobado que dentro de una o dos semanas después del incremento de las lluvias, se produce un aumento en el número de consultas por problemas respiratorios.

Existen enfermedades asociadas al cambio de clima. Así, cuando inicia la época húmeda o fría aumentan las enfermedades respiratorias. Durante la época fría, los cilios nasales, cuya función es similar a las pestañas, tienden a perder movilidad. Estos minúsculos 


\section{Enfermedades respiratorias asociadas al ciclo lluvioso}

Vol. 2, núm. 3., (2018)

Juan Antonio Vera Hinojosa; Jefferson Steven Rivera Moreira; Delia Jamiley Naranjo Piña; Delia María Andaluz León

vellos, que junto con el moco eliminan el polvo, permiten así más penetración de microorganismos a nuestro cuerpo, lo que aumenta el riesgo de enfermarse. La gripe o influenza, catarros, amigdalitis, bronquitis, sinusitis, neumonía, laringitis, manchas rojas en la piel, son algunos padecimientos que tienen mayor incidencia durante la temporada fría. (Diario El Mundo, 2017)

De acuerdo con la investigación de Rodríguez \& Sánchez (2000):

Las Infecciones Respiratorias Agudas están constituidas por un variado grupo de enfermedades causadas por diversos agentes causales que afectan uno u otra zona de las vías respiratorias, cuyas manifestaciones clínicas son bastante evidentes y de alguna forma se repiten en cada una de ellas. Estos signos o síntomas frecuentemente están dados por tos de menos de 15 días de duración, dificultad para respirar, estridor (ronquido), dolor o enrojecimiento faríngeo, otalgia, otorrea, rinorrea, obstrucción nasal. Entre las IRA (Infecciones Respiratorias Agudas) se encuentran aquellas infecciones leves como Resfrío o catarro, Faringitis, Amigdalitis, Bronquitis, Otitis o enfermedades graves como la Neumonía. (párr. 3)

Continúa (Rodríguez et al., 2000) haciendo referencia a la caracterización de algunas de las principales infecciones respiratorias agudas, y al respecto sólo se hará mención a la descripción de las mismas.

Resfriado. (Catarro común)

Ocurre cuando se presenta una inflamación del tracto respiratorio alto a causa de un virus. 


\section{Enfermedades respiratorias asociadas al ciclo lluvioso}

Vol. 2, núm. 3., (2018)

Juan Antonio Vera Hinojosa; Jefferson Steven Rivera Moreira; Delia Jamiley Naranjo Piña;

Delia María Andaluz León

Aunque los virus de la gripe se encuentran en cualquier ambiente, la exposición es más probable en lugares cerrados en contacto con otras personas. Existen cerca de 200 virus diferentes que pueden causar el catarro; entre los más comunes se encuentran los rinovirus, virus sincitial respiratorio, virus corona, parainfluenza e influenza.

La infección usualmente comienza con estornudos, dolor de garganta y tos no productiva.

Lo que diferencia la gripe de otras infecciones virales es la ausencia de fiebre alta. Después de 3 ó 4 días (una semana generalmente) la gripe comienza a aliviarse (Mayo Clinic Health Letter, 1993)

\section{Bronquitis Aguda}

Es una inflamación e irritación de los bronquios, causada generalmente por una infección viral o bacteriana. En los niños, los virus son la causa más común de bronquitis (Mayo Clinic Health Letter, 1993).

Sus síntomas incluyen tos con mucus, molestias en el pecho, fiebre y cansancio extremo.

\section{Neumonía}

Es una inflamación de los bronquios y los alvéolos pulmonares. Pueden existir alrededor de 30 causas diferentes, entre ellas, virus, bacterias, micoplasmas, hongos, agentes químicos. La infección típicamente sigue a un resfriado o a la Influenza, pero puede comenzar como una infección primaria en los pulmones.

Los síntomas típicos de una neumonía viral son tos seca con dolor de cabeza, fiebre, 


\section{Enfermedades respiratorias asociadas al ciclo lluvioso}

Vol. 2, núm. 3., (2018)

Juan Antonio Vera Hinojosa; Jefferson Steven Rivera Moreira; Delia Jamiley Naranjo Piña; Delia María Andaluz León

dolor muscular y fatiga. Ocasionalmente a la infección viral puede seguir una infección bacteriana.

Los síntomas de la neumonía bacteriana son fiebre alta y una tos que produce un esputo grueso, de color verde amarillento. Puede sentirse también escalofríos y dolor en el pecho al respirar.

\section{Influenza}

La influenza es una infección de las vías respiratorias superiores e inferiores causada por los virus de la influenza A y B.

La infección se caracteriza por la rápida aparición simultánea de fiebre, escalofríos, dolor de cabeza y fatiga. Es típico el dolor muscular, especialmente en la espalda, brazos y piernas. La fiebre puede mantenerse alta alrededor de tres días (9).

\section{Complicaciones}

Por lo general, estas infecciones en su mayoría son leves, sin embargo, de acuerdo a la condición general de un paciente un paciente, las mismas pudieran devenir en complicaciones amenaza la vida, como pudiera ser en el caso de la neumonía y la bronquitis. Especialmente esto va en relación a los síntomas en los niños, por una parte, ya que si en ellos se percibe un aumento en la frecuencia respiratoria, hundimiento en las costillas al respirar, ruidos extraños al respirar (silba el pecho), inapetencia, fiebre que no baja aunque se le administre medicamentos para ello, entonces podría estarse configurando una complicación respiratoria de la se ha hablado, y por la otra parte, en cuanto a los adultos, tales dificultades pudieran presentarse si se observa dificultad 


\section{Enfermedades respiratorias asociadas al ciclo lluvioso}

Vol. 2, núm. 3., (2018)

Juan Antonio Vera Hinojosa; Jefferson Steven Rivera Moreira; Delia Jamiley Naranjo Piña;

Delia María Andaluz León

al respirar, dolor en el pecho al respirar o toser, decaimiento o cansancio excesivo, fiebre mayor de 38,5 grados centígrados por más de dos días, entre otros síntomas. (Chávez, 2018)

\section{Exceso de Humedad}

En esta sección se hace referencia exclusivamente a la llamada humedad intramuros, es decir, el nivel de humedad existente en el ambiente de nuestros espacios habitables, como pueden ser los diferentes espacios de nuestro hogar, oficina o lugar de trabajo o áreas deportivas y recreativas delimitadas.

Lo trascendente del exceso de humedad no radica en el porcentaje de concentración de humedad que en sí pudiera presentarse en un ambiente determinado (que básicamente por encima de $60 \%$ ya es considerado perjudicial para la salud humana) sino más bien tiene que ver con la proliferación de los microorganismos que se reproducen en las superficies húmedas. Cuando el vapor de agua (humedad) ambiental que se encuentra en un determinado ambiente poco ventilado o asoleado se condensa, pasa a un estado líquido y estos fluidos por consiguiente terminan depositándose en superficies tales como: alfombras, paredes, techos, madera, entre otras, trayendo como consecuencia que las zonas más sombrías de la habitación tenderán a estar húmedas permanentemente, facilitando así las condiciones ideales para la proliferación de ácaros y moho. (Airalia.es, 2018)

En la misma fuente informativa se explica que los ácaros, son organismos microscópicos cuyo hábitat (entre otros) es el ámbito doméstico. Los ácaros viven preferentemente en ambientes de entre $70 \%$ y $80 \%$ de humedad. En casas con alto nivel de humedad ambiental su vida se prolonga y se reproducen mucho más. El problema es que tanto los excrementos de estos 


\section{Enfermedades respiratorias asociadas al ciclo lluvioso}

Vol. 2, núm. 3., (2018)

Juan Antonio Vera Hinojosa; Jefferson Steven Rivera Moreira; Delia Jamiley Naranjo Piña; Delia María Andaluz León

microorganismos como los propios ácaros muertos son los causantes de diferentes alergias respiratorias. Vivir en un ambiente por encima de un $60 \%$ de humedad ambiental puede llegar a ser devastador para personas con alergias respiratorias y asma.

Así mismo, continúa diciendo que el moho, es un tipo de hongo y se reproduce por esporas que vienen transportadas por el aire, y cuando éstas se depositan en una superficie húmeda a las que no llegan los rayos del sol, tales como pared, techo, alfombras, sábanas, almohadas y tapices, comida, madera, papel, entre otras superficies, en las que comienzan a alimentarse, creciendo y reproduciéndose a velocidad vertiginosa.

\section{Medidas de prevención}

A continuación, se mencionan algunas previsiones que pueden tomar tanto personas sanas (por ejemplo, caso de las maternas) como las que ya se encuentran afectadas por algún síndrome asociado a enfermedades respiratorias, teniendo como fundamento la información aportada en la noticia del equipo de investigación periodística de (El Espectador, 2018) vinculada al aumento de las Infecciones Respiratorias Agudas (IRA) por la entrada de la temporada de lluvia:

- Alimentar sólo con leche materna a los menores de seis meses y en el resto y no suspender la lactancia y Lavarse las manos varias veces al día. (Caso de las maternas).

- Utilizar tapabocas para evitar el contagio de personas cercanas.

- Evitar los cambios bruscos de temperatura, especialmente al salir de lugares cerrados o en momentos de lluvia.

- Evitar el consumo de cigarrillo y el contacto con persona fumadoras. 


\section{Enfermedades respiratorias asociadas al ciclo lluvioso}

Vol. 2, núm. 3., (2018)

Juan Antonio Vera Hinojosa; Jefferson Steven Rivera Moreira; Delia Jamiley Naranjo Piña;

Delia María Andaluz León

- Desinfectar los utensilios de la casa y juguetes de los menores, especialmente cuando un integrante de la familia tiene tos o gripe.

- Evitar enviar a los menores con gripe a las instituciones educativas o de cuidado infantil.

- Evitar las actividades físicas intensas al aire libre durante días de elevado nivel de humedad ambiental (preludio de lluvia).

- Ventilar todos los espacios posibles del hogar y del lugar de trabajo, así como limpiar todo rastro de polvo acumulado.

- Usar gafas de protección visual y lavarse las manos con agua y con jabón.

- Consultar al médico si se evidencian signos tales como fiebre, malestar general, congestión y secreción nasal, tos, dolor de garganta, expectoración y dificultad para respirar.

\section{Conclusiones.}

La enfermedad respiratoria sigue patrones temporales, tanto en las latitudes altas, presentando un incremento de estos casos en los meses de invierno; como en latitudes bajas (caso de los países tropicales) en los que se presentan tales casos con mayor frecuencia durante la temporada de lluvias. (Correal, Marthá, \& Sarmiento, 2015)

Este estudio pudiera considerarse, por una parte, material base de posteriores estudios enfocados en el diseño de sistemas de alerta temprana en salud pública, teniendo claro que para tales fines sería imprescindible el análisis de series de tiempo más extensas que permitan capturar las distintas escalas temporales de la variabilidad climática en las distintas zonas lluviosas de países tropicales en la región centro y suramericana; y por la otra, por ende no menos importante, considérese un aporte fundamental en el desarrollo de acciones preventivas 


\section{Enfermedades respiratorias asociadas al ciclo lluvioso}

Vol. 2, núm. 3., (2018)

Juan Antonio Vera Hinojosa; Jefferson Steven Rivera Moreira; Delia Jamiley Naranjo Piña; Delia María Andaluz León

orientadas a disminuir el impacto que ejerce el ciclo de lluvia en la proliferación de enfermedades respiratorias en países tropicales.

\section{Referencias Bibliográficas}

Agencia EFE. (21 de 12 de 2017). El Tiempo. Obtenido de El Tiempo: http://www.eltiempo.com/vida/medio-ambiente/el-cambio-climatico-facilita-el-contagiode-enfermedades-infecciosas-164112

Airalia.es. (27 de 07 de 2018). Airalia.es. Obtenido de Airalia.es: https://www.airalia.es/blog/losefectos-de-la-humedad-excesiva-en-la-salud/

Chávez, J. (16 de 05 de 2018). Revista Es. Obtenido de Revista Es: http://revistaes.com/comotratar-las-infecciones-respiratorias-virales-en-temporada-lluviosa/

Correal, M., Marthá, J., \& Sarmiento, R. (2015). Influencia de la variabilidad climática en las enfermedades respiratorias agudas en Bogotá. Biomédica, 35. doi:http://dx.doi.org/10.7705/biomedica.v35i0.2456

Diario El Mundo. (2017). Cambio climático: el causante de muchas enfermedades respiratorias. VidaSana, párr. 2-4.

El Tiempo. (21 de 02 de 2018). eltiempo.com. Obtenido de eltiempo.com: http://www.eltiempo.com/vida/salud/consejos-para-evitar-infecciones-respiratorias-enepoca-de-lluvias-184648

OMS. (2015). Organización Mundial de la Salud. Obtenido de http://www.who.int/nmh/countries/ecu_es.pdf

OMS. (01 de 02 de 2018). Organización Mundial de la Salud. Obtenido de Organización Mundial de la Salud: http://www.who.int/es/news-room/fact-sheets/detail/cambioclim\%C3\%A1tico-y-salud

OMS. (2018). Organización Mundial de la Salud. Obtenido de Organización Mundial de la Salud: http://www.who.int/topics/respiratory_tract_diseases/es/

Ríos, R. (09 de 2017). www.eumed.net. (E. Grupo de investigación (SEJ 309) eumed.net de la Universidad de Málaga, Ed.) Obtenido de www.eumed.net: http://www.eumed.net/libros/libro.php?id=1662 